\title{
La CEPAL, las empresas transnacionales y la búsqueda de una estrategia de desarrollo latinoamericana
}

\section{Daniel Kerner}

Departamentos de Historia

y de Economía

Universidad de Illinois

en Urbana-Champaign

kerner@uiuc.edu
En este artículo se analiza el papel que la CEPAL ha asignado a la inversión extranjera directa y a las empresas transnacionales en su propuesta de desarrollo, examinando la historia de la institución y sus publicaciones más representativas. Con impresionante continuidad en su visión y en sus recomendaciones de política, la CEPAL ha reconocido que la inversión extranjera es necesaria para apuntalar el desarrollo latinoamericano, pero ha aconsejado cautela ante sus consecuencias. Ha insistido en la regulación y vigilancia de las actividades de las transnacionales; tras tales recomendaciones está la idea de que el desarrollo económico de América Latina debe ser liderado por industrias de propiedad latinoamericana. Y ha destacado las ventajas de la integración latinoamericana, que contribuye a expandir las industrias de la región, promueve la investigación y el desarrollo autóctonos y brinda a los gobiernos de América Latina información y poder de negociación frente a las empresas transnacionales. 
Esencialmente, el debate se define por dos grandes preguntas: una, ¿dónde está la responsabilidad por nuestro rezago? ¿En nosotros o en el mundo exterior que nos explota? Dos, ¿cómo podemos progresar? ¿Imitando a otros (occidente o Rusia) o forjándonos nuestro propio camino? Albert O. Hirschman

\section{Introducción}

La historia económica de los últimos 50 años registra asombrosos cambios en todo el mundo. Durante este período, los países de América Latina se han embarcado en un proceso de industrialización mediante la sustitución de importaciones y su relación con la economía internacional se ha visto profundamente alterada. La CEPAL ha cumplido un papel fundamental en este proceso. Desde sus inicios, al ofrecer un marco teórico conciso desde el cual se lanzó la industrialización mediante la sustitución de importaciones, hasta nuestros tiempos neoliberales, sus análisis y recomendaciones siempre han ocupado un lugar importantísimo en los debates políticos e intelectuales latinoamericanos.

El propósito de la industrialización mediante la sustitución de importaciones era reducir la vulnerabilidad externa de América Latina y encaminarla en el sendero del desarrollo. Sin embargo, la región sufría de problemas graves y arraigados: escasas fuentes de inversión, falta de capital y desventaja tecnológica. En el presente trabajo se intenta investigar cómo la CEPAL abordó estos problemas y determinar el papel que el capital externo y las empresas transnacionales (ET) debían cumplir en la estrategia de desarrollo que la institución contemplaba. Se examinará la función que originalmente se preveía para la inversión extranjera, cuando se propuso la industrialización mediante la sustitución de importaciones por primera vez, y cómo esta visión se modificó con el transcurso de los años, a medida que avanzó el proceso de industrialización y que la participación de las empresas transnacionales y la inversión extranjera directa (IED) aumentó y cambió. También se analizará la relación entre estos cambios y la evolución y los desafíos teóricos, como la teoría de la dependencia y las ideas neoliberales. Dicho análisis se realizará examinando las diferentes etapas del

$\square$ El autor agradece a Joseph Love, Guillermo Guajardo, Michael Monteón y dos jueces anónimos de la Revista de la CEPAL sus valiosas e incisivas observaciones. pensamiento cepalino e interpretando el papel que la IED y las empresas transnacionales cumplen en cada una. Se sostendrá que, aun cuando se ha producido una evolución profunda y la atención prestada al capital externo y a las empresas transnacionales ha crecido con el tiempo, la posición al respecto ha persistido: la IED y las empresas transnacionales son útiles e incluso necesarias como medio de acceder al capital y a la tecnología que hacen posible la industrialización, ya que funcionan como fuentes de difusión tecnológica y dinamismo económico. Sin embargo, siempre corresponde alzar una voz de alerta: es preciso estar consciente de las crisis de las balanzas de pagos y del aumento de la dependencia externa. De ahí las políticas de participación selectiva y de control de las empresas transnacionales propuestas por la CEPAL, el carácter transitorio asignado a la IED y la idea de la integración regional. En todo el período, la noción de que las industrias de propiedad de la región debieran ser las fuerzas rectoras del desarrollo económico persiste en el pensamiento cepalino.

En este trabajo se examinará la posición de la CEPAL respecto de las empresas transnacionales en cada una de sus cinco décadas de existencia, que coinciden a grandes rasgos con las etapas de su desarrollo intelectual. ${ }^{1}$ En la primera parte se analiza el decenio de 1950, en el que surgió el pensamiento cepalino. La preocupación por el capital externo estuvo presente desde el principio, pero aumentó con el correr del decenio, mientras se hacía hincapié en atraer fondos públicos. En la segunda parte se trata el decenio de 1960, en que adquiere relevancia la necesidad de encarar el tema de las empresas transnacionales y se evalúan por primera vez sus aportes positivos y negativos, a la luz del creciente reconocimiento de que había que reformar la industrialización sustitutiva de las importaciones e ir más allá. Además, en esa década se

\footnotetext{
${ }^{1}$ La división en períodos se basa en Bielschowsky (1998a, pp. 11-12).
} 
destaca cada vez más el tema de las empresas transnacionales y el capital externo. Durante la década de 1950 se hacía hincapié en la necesidad de atraer capital público del exterior; en la de 1960, y en mayor medida posteriormente, ganó terreno la conveniencia de preocuparse por la inversión extranjera privada y crear medios para atraerla. En esta etapa las empresas transnacionales se consideraban un medio de fomentar las exportaciones de manufacturas - postura que aparece en el decenio de 1950 y cobra fuerza en los siguientes-, ya que se evidenciaban las limitaciones de la industrialización sustitutiva de las importaciones y aumentaba la importancia mundial de las empresas transnacionales. Luego se considera la década de 1970, marcada por el análisis de los "estilos de desarrollo". En esta tercera etapa se destacan los límites de la contribución de las empresas transnacionales, dado el es- tilo de desarrollo de la región. De hecho, el análisis de estas empresas pasa a ocupar un lugar fundamental en los estudios de la CEPAL. Por último, se examinan las décadas de 1980 y de 1990, en que sobresale la idea de la "transformación productiva con equidad". La atención prestada a las empresas transnacionales y al capital externo es aún mayor, especialmente porque en el decenio de 1990 se reanudan las corrientes de capital hacia la región, se reconoce la necesidad de abrir las economías y se insiste en la necesidad de atraer a dichas empresas para que aporten tecnología y capital. Sin embargo, la idea de que las empresas latinoamericanas deben guiar la estrategia de desarrollo se mantiene, junto con el reconocimiento de los aspectos positivos de la industrialización mediante la sustitución de importaciones. En cada etapa se considera el contexto intelectual y económico internacional.

\section{II}

\section{El decenio de 1950: los primeros años}

En 1949 la CEPAL, con la autoría de Raúl Prebisch, publicó su "manifiesto", en el cual sentó las bases de su concepción de los problemas económicos de América Latina (Prebisch, 1949). El punto de partida de ese documento era la particular posición de productor y exportador de productos primarios que América Latina había llegado a ocupar en el sistema económico internacional. Tal posición correspondía a los postulados de la teoría de la ventaja comparativa, pero, según Prebisch, el desempeño económico y la situación por la que atravesaba la periferia contradecían las predicciones de esa teoría de que los incrementos de productividad que se estaban registrando en los países industrializados se transferirían en forma pareja a todo el sistema. Por el contrario, Prebisch observó que los términos de intercambio de la región se habían estado deteriorando en el largo plazo, lo que obedecía en parte al hecho de que la mano de obra del centro estaba mejor organizada. En la fase descendente del ciclo económico, estos grupos se resistían a las reducciones salariales. Los trabajadores rurales de América Latina no estaban organizados y por eso no podían resistir las presiones a la baja, con lo cual el ajuste necesario en el centro se transfería a la periferia. Otro factor importante era el poder monopólico que ostentaban las industrias del centro. En escritos posteriores, apareció otro factor que explicaba la tendencia al deterioro de los términos de intercambio. Era la inelasticidad de la demanda de productos primarios en el centro. Conocida como la ley de Engel, postula que, en la medida que crece el ingreso, la proporción de la demanda de bienes primarios tiende a declinar. En la periferia, en cambio, se registraba de hecho una demanda inelástica de importaciones industriales. Esta explicación, que pasó a denominarse la tesis Prebisch-Singer, se convirtió en la marca característica de la CEPAL.

Si la industrialización era necesaria para resolver los problemas de la región, dados el deterioro de los términos de intercambio, las características estructurales de la periferia, el escaso ahorro y la disparidad tecnológica con el centro, el proceso debía hacerse mediante la sustitución de importaciones, lo que significaba que el Estado debía alentar y proteger a las nuevas industrias.

Prebisch entendía que el urgente problema de la falta de ahorro para la inversión exigía recursos distintos de los del Estado. Una posibilidad que contemplaba era el capital externo. ${ }^{2}$ Aun cuando el problema

\footnotetext{
${ }^{2}$ Pese a que en general se piensa que Prebisch tenía un sesgo antiexportador, se sabe que desde el inicio creyó que la industrialización mediante la sustitución de importaciones no significaba "que la exportación primaria había de sacrificarse", ya que suministraba divisas y por lo tanto se necesitaban inversiones para aumentar la productividad del sector exportador agrícola (Prebisch, 1949).
} 
del capital externo estuviera presente desde el inicio, comenzó a prestársele más atención a medida que transcurrió el decenio de 1950. La primera reflexión sistemática al respecto surgió en $1954 .^{3}$ El capital externo "aparece como un medio de contar con los recursos adicionales de divisas que harían falta para sostener una elevada tasa de desarrollo y eliminar simultáneamente la diferencia entre la demanda de importaciones que ello implicaba y las entradas propias y regulares por concepto de exportaciones" (CEPAL, 1969, p. 33). También se necesitaba como medio de complementar el ahorro interno.

La escasez de capitales externos disponibles para invertir en América Latina en los años cincuenta era motivo de gran preocupación para la CEPAL. ${ }^{4}$ Prebisch explicaba que las inversiones extranjeras habían cumplido una función importantísima en la anterior estrategia de desarrollo, sobre todo en el establecimiento de infraestructura a través de la IED y el mercado de bonos. Sin embargo, el mercado de bonos había dejado de ser accesible para los países latinoamericanos desde la cesación de pagos de los años treinta. En consecuencia, dada la situación internacional y debido a la necesidad de reducir el costo de las inversiones, estimaba que la mejor solución era que las instituciones de crédito internacional prestaran ayuda. Dichas instituciones debían dar fácil acceso a los recursos para que los países de América Latina los destinaran a la inversión en capital social (CEPAL, 1954, p. 16). Ello debía ser "al menos mientras no vuelva a abrirse el mercado de bonos privados" (ibid., p. 16). Proponía una política de cooperación internacional en virtud de la cual los países industrializados, especialmente por conducto de estas instituciones internacionales, brindarían capital e inversiones a América Latina. No era preciso que fuera un tipo de Plan Marshall, ya que el desarrollo de América Latina requería "empréstitos productivos de plazos holgados y de intereses tan bajos como los que permitan los mercados financieros" (ibid., p. 24). Previno que debía ser un alivio temporal, hasta que el desarrollo de las industrias latinoamericanas les permitiera generar sus propios recursos. Este carácter transitorio de los recursos externos se mantendría como

\footnotetext{
${ }^{3}$ Sin embargo, Prebisch abordó este tema en El desarrollo económico de América Latina y algunos de sus principales problemas: "Además del ahorro presente, inversiones extranjeras bien encaminadas podrían contribuir al aumento inmediato de la productividad por hombre" (Prebisch, 1949).

${ }^{4} \mathrm{La}$ CEPAL estimaba que en los primeros tres años de la década de 1950 la IED total sólo había ascendido a 1600 millones de dólares (CEPAL, 1954, pp. 14-15).
}

una preocupación fundamental de la CEPAL. Otro aspecto importante era que el capital extranjero debía ascender a un monto suficiente para producir efectos favorables sobre el desarrollo de la región. ${ }^{5}$ El objetivo de esta política no sólo se concentraba en la inversión, sino también en aumentar el coeficiente de ahorro y fomentar nuevas inversiones (CEPAL, 1954, p. 21). Una propuesta destacada fue canalizar los fondos internacionales a empresas de América Latina a través de ciertas instituciones estatales (ibid., p. 32). Por ejemplo, reconociendo las deficiencias institucionales de la región, sobre todo de instituciones financieras, la CEPAL propuso crear un Fondo Interamericano de Desarrollo Industrial, Agrícola y Minero. Dicho fondo, basado en planes de desarrollo nacional para cada país, se haría cargo de los recursos disponibles (ibid., p. 148).

El otro problema que Prebisch reconocía era la desventaja tecnológica de las industrias latinoamericanas y el alto costo de mantenerse al día y obtener la tecnología del centro. Era preciso contar con algún tipo de participación de las empresas transnacionales para que América Latina tuviera acceso a la tecnología más moderna. No obstante, ello debía hacerse de forma programada y cautelosa. La participación de las empresas transnacionales no debía ser generalizada sino orientada por el Estado y en sectores determinados de la economía. Además, lo ideal sería firmar acuerdos entre industrias para la participación conjunta, la asistencia tecnológica y la capacitación del personal (CEPAL, 1954, p. 41). Ello permitiría que las industrias de América Latina compitieran desde una posición más favorable (ibid., p. 30). La participación indiscriminada iría en desmedro del objetivo de la industrialización mediante la sustitución de importaciones. Como en el caso de las inversiones, Prebisch pensaba que era necesario formular una estrategia de cooperación internacional en virtud de la cual los países avanzados industrializados ayudarían a América Latina con programas concretos de asistencia tecnológica.

Otra propuesta conexa, presente desde 1949, fue la creación de un Mercado Común Latinoamericano (Prebisch, 1949, p. 6). La lógica de esta propuesta era que ofrecería a las nuevas industrias un mercado más grande y fomentaría las economías de escala, con lo cual las industrias latinoamericanas estarían en mejores condiciones de competir. El ingreso de IED a la región sería alentado y controlado, de la manera antes descrita, si

\footnotetext{
${ }^{5}$ Lo que era coherente con la posición de la CEPAL de recurrir a la programación y hacer hincapié en ella. Véase Hirschman (1961).
} 
se realizaba dentro del mercado común y a través de políticas coordinadas entre los gobiernos de América Latina, lo que constituiría una importante forma de reducir la vulnerabilidad externa de la región gracias a una política regional anticíclica (CEPAL, 1954, p. 150).

Sin embargo, estas ideas no estaban de acuerdo con los proyectos de posguerra de los Estados Unidos. Entre las metas de seguridad contempladas por los políticos estadounidenses figuraba la integración del Tercer Mundo en la economía mundial, pero de una manera en que el entorno económico internacional estuviera abierto al comercio y las inversiones estadounidenses (Painter, 1999, p. 14). La búsqueda que la CEPAL emprendió en pos de la autonomía y el control de las empresas extranjeras (que en este período eran principalmente estadounidenses) constituía un franco obstáculo para los proyectos del país del Norte. Además, si bien el gobierno estadounidense apoyaba el proceso de integración de Europa, en América Latina se consideraba inconveniente un proyecto con ese fin. Por último, la idea de Prebisch de la asistencia económica no prosperó, ya que los Estados Unidos declinaron las solicitudes de ayuda económica y recurrieron a los militares y las elites tradicionales para mantener un clima favorable a la inversión extranjera. Así pues, la asistencia estadounidense y, por ende, internacional se dirigió principalmente a Europa y Asia (Painter, 1999, pp. 21-24). La tensión resultante entre el proyecto de la CEPAL y los intereses de los Estados Unidos seguiría siendo, durante los siguientes 50 años, un fuerte motivo de presiones para aceptar el proyecto cepalino.

\section{III}

\section{La transformación de la industrialización sustitutiva de importaciones: el decenio de 1960}

Los primeros años de la industrialización sustitutiva de importaciones (ISI) dieron resultados ambiguos. Por un lado, con altos aranceles de protección y políticas estatales expansivas, la industrialización avanzó a gran ritmo y los países latinoamericanos registraron una notable tasa de crecimiento. ${ }^{6}$ En la década de 1960, la industria se había transformado en el motor de la economía en los países más grandes, y en toda la región su importancia crecía. ${ }^{7}$ No obstante, el proceso pronto tropezó con serios problemas. El más evidente fue que el coeficiente de importaciones había aumentado y se había orientado hacia los bienes de capital (FfrenchDavis, Muñoz y Palma, 1998, p. 190). En consecuencia, las crisis de la balanza de pagos no sólo se hicieron más frecuentes, sino que su impacto fue más agudo. Aun más que en el período anterior, el desempeño de la economía se vio gravemente afectado por las crisis externas.

\footnotetext{
6 Véase una reseña del período y del desempeño económico de la región en Ffrench-Davis, Muñoz y Palma (1998, p. 187). En el decenio de 1950 el PIB de América Latina creció a una tasa del 5.1\%. ${ }^{7}$ Para 1960 su participación en el PIB era del 21\% en la región, y alcanzaba cifras superiores en los países más grandes (Ffrench-Davis, Muñoz y Palma, 1998, p. 187).
}

En esta década América Latina también asistió al nacimiento y desarrollo de la teoría de la dependencia, que obedecía a distintas influencias, pero los problemas mencionados de la isi y el desencanto con la industrialización como medio de reducir la vulnerabilidad externa son los factores que más importancia tuvieron. ${ }^{8}$ En contraste con lo que Prebisch y los primeros escritos de la CEPAL sostenían, los defensores de la teoría de la dependencia explicaban que el subdesarrollo de la periferia no era producto de una estrategia de desarrollo determinada, sino resultado del desarrollo del sistema. Con la revolución cubana, un enfoque más radical que el cepalino comenzó a ganar terreno en la interpretación de los problemas latinoamericanos y en la búsqueda de soluciones.

Aun así, a principios de la década de 1960 reinaba un clima internacional positivo para las ideas de la CEPAL, ya que el gobierno de Kennedy, preocupado por el ejemplo de Cuba, cambió sus políticas de seguridad internacional y volvió su atención hacia

\footnotetext{
${ }^{8}$ Los orígenes de la teoría de la dependencia son por cierto mucho más complejos. Dada la amplia gama de escuelas de la dependencia, se hace aún más difícil determinarlos. Véase al respecto Love (1996a, pp. 182-201).
} 
América Latina, con un enfoque más favorable. Influido por la teoría de la modernización, su idea era que la "amenaza comunista" debía controlarse mediante el desarrollo económico del Tercer Mundo. Con este fin, en marzo de 1961 lanzó la Alianza para el Progreso, en cuyo marco se debían enviar a la región 20000 millones de dólares en ayuda extranjera en un plazo de 10 años, de los cuales la mayor parte provenía del Gobierno de los Estados Unidos. De especial importancia fue el hecho de que las ideas de reforma estructural y de planificación lograron mayor legitimidad, ya que eran las metas de la Alianza para el Progreso (Montecinos, 1997). Además, la Alianza estaba de acuerdo con la idea original de Prebisch sobre el tipo de inversión extranjera necesaria en América Latina. Sin embargo, para mediados de la década los resultados de la ayuda externa estaban lejos de ser significativos, en especial con respecto a las reformas estructurales. Debido a los desalentadores resultados de Vietnam, la tumultuosa situación política interna de los Estados Unidos y la creciente inestabilidad del Tercer Mundo, la política exterior estadounidense se apartó de la ayuda y el fomento del desarrollo económico, concentrándose en la seguridad, razón por la cual apoyó y alentó los golpes militares en toda la región (Painter, 1999, pp. 63-64).

A la luz de los problemas reales con que tropezó la industrialización sustitutiva de las importaciones y la consiguiente inestabilidad macroeconómica, y en un clima intelectual marcado por la teoría de la dependencia, la CEPAL necesitaba revisar sus análisis y sus recomendaciones de política. ${ }^{9}$ Entró en esta nueva etapa de su historia intelectual con renovados análisis y propuestas. Contrariamente a lo que sus críticos afirman, Prebisch y la CEPAL reaccionaron rápidamente a esta nueva situación. ${ }^{10}$ En Hacia una dinámica del desarrollo latinoamericano, Prebisch reconoció y destacó la falta de dinamismo de la industrialización sustitutiva. Encontraba dos problemas principales: las limitaciones externas e internas (Prebisch, 1963, p. 15).

Dados los desequilibrios externos que la industrialización sustitutiva había provocado, Prebisch recomendó un proceso de industrialización más profundo,

\footnotetext{
${ }^{9}$ La CEPAL nunca apoyó realmente la teoría de la dependencia, aunque algunos de sus representantes trabajaban en la institución. Además, dicha teoría evolucionó a partir de ideas estructuralistas, e incluso Prebisch contribuyó a desarrollarla y difundirla (Love, 1996b).

${ }^{10}$ Por ejemplo Harberger menciona que la "buena economía" se enfrentaba al baluarte del aislamiento y proteccionismo doctrinarios: la vieja CEPAL, que apoyaba y fomentaba activamente las políticas intervencionistas, estatistas y antiliberales de la época (Harberger, 1996, p. 306).
}

que se orientara hacia los bienes intermedios y de capital, reduciendo así las restricciones a la balanza de pagos. Las limitaciones externas obedecían no sólo al aumento de las importaciones, sino también a la falta de dinamismo de las exportaciones. Juntamente con este problema, Prebisch observaba el continuo deterioro de la relación de precios del intercambio de la periferia. Por esta razón expresó la necesidad imprescindible de actuar en dos frentes, con el aumento de las exportaciones de manufacturas hacia diversos mercados, incluidos los del centro, sin descuidar las exportaciones tradicionales, y la defensa de la relación de precios del intercambio (Prebisch, 1963, p. 105). Otro importante elemento para fomentar las exportaciones fue el proceso de integración en un Mercado Común Latinoamericano (Ffrench-Davis, Muñoz y Palma, 1998).

Por ese entonces la CEPAL destacaba también la importancia de los problemas sociales de la región. ${ }^{11}$ "La estructura social prevaleciente en América Latina opone un serio obstáculo al progreso técnico y, por consiguiente, al desarrollo económico y social" (Prebisch, 1963, p. 4). Mencionaba "la notoria insuficiencia de la acumulación de capital exigida por la tecnología contemporánea frente al módulo exagerado de consumo de los grupos de altos ingresos" (ibid., p. 13). Las reformas estructurales, como la reforma agraria, se consideraban esenciales. "América Latina tiene que acelerar su ritmo de desarrollo económico y redistribuir el ingreso en favor de las masas populares" (ibid., p. 12).

La política sustitutiva de las importaciones había agravado el estrangulamiento exterior y los problemas de capital e inversión persistían. Además, debido al carácter de las industrias que se desarrollaban en América Latina, la región aún adolecía de una significativa desventaja tecnológica. El proceso de industrialización, al menos en los países más grandes y que más habían avanzado, había llegado a su fin (Prebisch, 1963, p. 88). Era preciso aplicar una política para restringir el consumo de los grupos de altos ingresos y fomentar las exportaciones. Sin embargo, aún se necesitaba capital, inversión y tecnología extranjeros para que la estrategia de la CEPAL diera resultado. "Necesitamos del extranjero para que nos ayude a desenvolver nuestra propia aptitud, para hacerlo incorporando toda la masa de la población al desarrollo" (Prebisch,

\footnotetext{
${ }^{11}$ Lo que coincide con la cambiante percepción del desarrollo en la teoría económica, desde una concepción basada en el desarrollo como crecimiento del PIB a otra en que los aspectos sociales pasaban a ser elementos de la definición del desarrollo. Véase Arndt (1987, cap. 4).
} 
1963, p. 65). Como antes, la inversión extranjera era necesaria en forma transitoria, hasta que la región pudiera generar sus propios recursos y tecnología.

Por consiguiente, el papel de la IED y las empresas transnacionales se reinterpretó en esta nueva etapa, por la influencia no sólo de los acontecimientos generales ya mencionados, sino también por el desencanto con la estrategia anterior. Prebisch había hecho hincapié en la asistencia internacional pública y las instituciones financieras, pero ello no había resuelto los problemas. En la década de 1950 la IED había representado el $60 \%$ del total de movimientos de capital. Sin embargo, a principios del decenio de 1960, siguiendo el espíritu de la Alianza para el Progreso, se pasó a destacar los empréstitos oficiales, nuevamente conforme a las ideas de Prebisch (Ffrench-Davis, Muñoz y Palma, 1998).

En la década de 1960 el énfasis, en términos del capital extranjero, se desplazó hacia la IED y las empresas transnacionales. Ahora Prebisch sostenía que en esta nueva era "se precisa establecer una clara distinción entre estos dos tipos de capital extranjero: el pretérito, con los enclaves que aún subsisten, y el nuevo tipo de capital, que se incorpora resueltamente al proceso intensivo de industrialización" (Prebisch, 1963, p. 66). "La empresa extranjera tiene que ser un núcleo de irradiación tecnológica" (Prebisch, 1963, p. 65). No obstante, aun cuando la participación de las empresas transnacionales y la IED se veía desde una perspectiva más favorable, igualmente se expresaban reservas respecto de su presencia y sospechas sobre los beneficios reales que traería. Un problema eran las copiosas ganancias de algunas firmas: "Es indudable que el incentivo de la ganancia es indispensable para atraer la iniciativa privada extranjera. Sin embargo, esto tiene que ser consecuencia del progreso técnico que ella aporta, de las nuevas formas de producción, organización y mercadeo que introduce en el medio local" (Prebisch, 1963, p. 66). Sin embargo, no es lo que ocurre habitualmente en la práctica, debido a la excesiva protección y la inflación. Las empresas transnacionales podían ocupar un lugar en un plan de desarrollo, siempre que estuviera determinado y regulado con claridad, para lo cual la intervención del Estado era ineludible. Prebisch pensaba que la iniciativa extranjera podía desempeñar un papel muy importante en un "programa de aliento a las exportaciones", por su "conocimiento de las prácticas de exportación y de los mercados del exterior", que en general no poseían las firmas nacionales (ibid., p. 67). La CEPAL había reconocido la necesidad de fomentar las exportaciones desde la década de 1950, y en el siguiente decenio esta idea pa- saría a ser un pilar de sus propuestas (Bielschowsky, 1998a, pp. 22-23). Prebisch ahora pensaba que las empresas transnacionales podrían contribuir en esta tarea. Otra posibilidad era una "asociación de la iniciativa extranjera con la latinoamericana, que puede ser una solución muy conveniente, desde el punto de vista de la irradiación tecnológica así como de la mejor convivencia con los intereses nacionales" (Prebisch, 1963, p. 67). En suma, latente en todas estas propuestas estaba la necesidad de formular políticas definitivas y claras, como las exenciones fiscales. "De lo contrario, la inversión extranjera podría tener excesiva gravitación en algunas ramas de la actividad económica, cosa inconveniente desde distintos puntos de vista" (ibid., p. 67). Dada la posición cauta respecto de las empresas transnacionales, las soluciones que Prebisch contemplaba para este dilema eran, por un lado, avanzar en el proceso de integración regional, lo que crearía una industrialización más eficiente en la región, nuevamente gracias a la especialización, la complementariedad, los mayores mercados y las economías de escala. En este sentido, la industria latinoamericana podría hacer "frente a la iniciativa extranjera, combinándose con ella en comunes empeños o compitiendo como iguales" (ibid., p. 119). Por otra parte, el proceso de integración podría también fomentar la investigación y el desarrollo autóctonos, ya que habría más incentivos para las industrias, lo que facilitaría la coordinación de políticas entre los Estados latinoamericanos para alentar la investigación y el desarrollo. Una parte complementaria de la estrategia era que los Estados debían tomar medidas definitivas para promover la investigación que produjera una tecnología más adecuada y eficiente.

Paralelamente a la regulación estatal de las empresas transnacionales, otra idea importante que surgió en este período, y que debe relacionarse con la búsqueda permanente de Prebisch de un programa internacional de cooperación, fue la propuesta de un código internacional de conducta que regulara las operaciones de las empresas transnacionales, lo que podía considerarse una respuesta al hecho evidente de que aumentaban las operaciones de esas empresas en la región. Es importante señalar que también se trataba de una preocupación constante que Prebisch promovió en la Conferencia de las Naciones Unidas sobre Comercio y Desarrollo (UNCTAD). ${ }^{12}$

\footnotetext{
12 Prebisch se marchó de la CEPAL y fue nombrado director de la UNCTAD en 1964. Dejó ese puesto en 1969, desencantado por la falta de apoyo y lo que él consideraba los magros logros de la UNCTAD. Véase Dosman y Pollock (1998).
} 
Como se mencionó, las ideas de la dependencia surgieron y evolucionaron, en parte, en la CEPAL durante el decenio de 1960. La generación más joven que trabajaba en el marco del paradigma de la dependencia también reflexionó sobre el papel del capital extranjero y las empresas transnacionales. Entre estos economistas se destacaba el chileno Osvaldo Sunkel. Según Sunkel, se podía "afirmar que hasta mediados de la década de 1950 prevalecieron formas y modalidades de incorporación de recursos financieros, humanos, tecnológicos y materiales externos que contribuyeron al desarrollo de una industria esencialmente nacional en América Latina. Pero a partir de ese momento, superadas las décadas de crisis y de Segunda Guerra Mundial, y coincidiendo con la expansión acelerada del conglomerado transnacional y de una nueva etapa en la sustitución de importaciones en América Latina, comienza la fase de la desnacionalización y sucursalización de la industria latinoamericana." (Sunkel, 1998, p. 513). Este último acontecimiento, pensaba Sunkel, era uno de los elementos más importantes que habían incidido en los resultados desalentadores que exhibía el proceso de industrialización (ibid., p. 513). Además, Sunkel pensaba que el mundo probablemente estaba en pleno "proceso de incorporación a una nueva modalidad del modelo centro-periferia, del cual creíamos que la industrialización por sustitución de importaciones nos estaba liberando." En este nuevo modelo aparecía "una nueva forma de división internacional del trabajo y su correspondiente agente: los oligopolios manufactureros transnacionales" (ibid., p. 515). Este modelo implicaba consecuencias importantes, como la persistencia y aun agudización del carácter monoexportador, el hecho de que el impulso dinámico de la economía provenía del exterior y que también fueran externos los centros de decisión fundamentales. Sunkel también creía que la mayor presencia de las transnacionales agravaría el problema del endeudamiento externo. Por último, advertía que el proceso de integración latinoamericana podía liquidar definitivamente la empresa privada nacional, al favorecer a la empresa extralatinoamericana, lo que podría sobrevenir si se creaban "condiciones en que la empresa nacional no sólo queda desfavorecida sino además incapacitada de obtener protección del Estado nacional" (ibid., p. 516). La evaluación final era que "la característica principal del sistema actual y probablemente del sistema futuro de las relaciones económicas internacionales es la penetración de la economía de los países subdesarrollados por el agente económico más poderoso de la economía de los países desarrollados y, muy en particular, por aquellos de la economía estadounidense, el centro predominante del sistema capitalista en la actualidad." (ibid., p. 531).

\section{IV}

\section{El derrumbe y los "estilos de desarrollo": el decenio de 1970}

Desde mediados de la década de 1950 los gobiernos de toda la región habían intentado atraer la IED y las empresas transnacionales de manera irrestricta. En este período se registró un gran incremento del ingreso de IED a América Latina, atraída por altas tasas de protección. Nuevas empresas transnacionales se incorporaron a la región para ocupar las principales posiciones en la producción de bienes manufacturados e intermedios. Sin embargo, fue una desilusión, ya que con frecuencia el capital se reunía a nivel local, muchas inversiones representaban la adquisición de una firma ya existente y no había garantía de que el vendedor fuera a reinvertir el producto de la compra en el mercado local (Bulmer-Thomas, 1994, p. 359). Este fenómeno sólo aumentó en el decenio de 1960, en que el comercio internacional y sobre todo el comercio de manufacturas continuaron creciendo de manera monumental. La industrialización sustitutiva había avanzado a otra etapa en los países más grandes, pero los problemas sólo se agudizaron. La inestabilidad política y económica, el aumento de la inflación y los mayores desequilibrios externos pasaron a ser fenómenos comunes en los países de la región. Estos acontecimientos económicos y políticos y la difusión de la teoría de la dependencia lograron propagar una visión negativa de la industrialización mediante la sustitución de importaciones. El papel que la IED y las empresas transnacionales habían venido a desempeñar en América La- 
tina sólo reforzó las sospechas de los teóricos de la dependencia, cuya voz se oía con fuerza cada vez mayor en los círculos intelectuales tanto de América Latina como del mundo desarrollado. ${ }^{13}$

Al iniciarse la década de 1970, los países de América Latina enfrentaron problemas externos y de inestabilidad aún más constantes. La crisis del petróleo de 1973 puso fin a la "edad dorada" y comenzó un período de inestabilidad financiera internacional, reducido crecimiento de los países industrializados y aumento de la inflación. Los efectos de esta crisis ejercieron enormes presiones sobre la estrategia de desarrollo aplicada por América Latina, especialmente los países importadores de petróleo. En este período también cobró mayor importancia la posición de las escuelas monetaristas, que atacaron ferozmente la estrategia de la industrialización sustitutiva.

Pese a todos los problemas, la gran disponibilidad de corrientes financieras en el mercado internacional permitió que los países latinoamericanos continuaran con profundas reformas, siguiendo una estrategia impulsada por la deuda. Debido a esta situación, la deuda externa de estos países habría de aumentar exponencialmente al cabo de la década. Sin embargo, varios gobiernos de la región trataban de fomentar las exportaciones industriales. De hecho, las exportaciones de manufacturas siguieron creciendo en todo este período, aunque nunca lograron alcanzar el nivel necesario para compensar por la escasez de divisas (Ffrench-Davis, Muñoz y Palma, 1998).

En esta situación la CEPAL entró en su tercera etapa, caracterizada por la idea de los "estilos de desarrollo" (Bielschowsky, 1998b, p. 34). La idea era que el problema de América Latina estribaba en el estilo de desarrollo que se estaba siguiendo. El principal argumento era que lo importante residía en la estructura social y política y en el poder y las relaciones desiguales que de ella surgían. ${ }^{14}$ Era la distribución de poder

\footnotetext{
${ }^{13}$ No obstante, cabe señalar que uno de sus miembros más prominentes, Fernando Henrique Cardoso, no tenía una visión tan negativa de las empresas transnacionales, lo que se observa en Dependencia y desarrollo, pero que aparece con mayor claridad después de acuñar el concepto de "desarrollo dependiente asociado". Cardoso afirmaba que la visión que oponía a las empresas transnacionales con el crecimiento y el desarrollo era errónea. Para él, las empresas transnacionales necesitaban de un mercado dinámico para funcionar, y así podían fomentar tanto el crecimiento como el desarrollo. Dadas las características del sistema internacional y la periferia, el hecho de atraer a esas empresas era una manera factible de que disponían los países de la periferia para llegar a su posible tasa de desarrollo (Cardoso, 1973, pp. 142-176).

${ }^{14}$ Estas ideas se hallan principalmente en Pinto (1976, pp. 97-128).
}

e ingresos lo que determinaba el resultado de la estrategia de desarrollo. Por lo tanto, para que el proceso de industrialización tuviera éxito, el principal problema que había que atacar era la distribución del ingreso. Esta idea no era nueva, pero adquirió más importancia analítica y se replanteó en un marco más amplio. Lo mismo podía decirse de la necesidad de las exportaciones de manufacturas, idea que cobró importancia en ese momento.

La gravitación económica de las empresas transnacionales era tal que la CEPAL reconoció que "no cabe duda de que el futuro de la región necesariamente tendrá que contemplar distintos grados y modalidades de convivencia con este tipo de unidades económicas" (CEPAL, 1981). La presencia de tales empresas creció significativamente en los estudios de la CEPAL y pasó a ser un foco central de atención, más que un aspecto de análisis más amplios.

Aníbal Pinto, al estudiar la internacionalización de la economía de posguerra, reconoció que las empresas transnacionales habían llegado a cumplir un papel importante en los sectores más dinámicos de las economías latinoamericanas, en especial en las más grandes (Pinto, 1980, p. 42). A fines del decenio de 1960 su penetración en la manufactura era particularmente marcada, ya que a las empresas extranjeras correspondía entre el $30 \%$ y el $40 \%$ —en los países más grandes - de la producción total (Bulmer-Thomas, 1994, p. 315).

Las empresas transnacionales habían llegado a América Latina y se habían adaptado al particular "estilo de desarrollo" de la región, marcado por su desigual distribución del ingreso. Existía una "contradicción entre los objetivos transnacionales de esas empresas y los objetivos nacionales encaminados al logro de un estilo de desarrollo integrador y autónomo". En el plano "interno se expresaría en especial en la orientación de la estructura productiva, que se adecua a la demanda restrictiva y elitista de los estratos de mayores ingresos, y en el externo, en la incapacidad de las empresas transnacionales para solucionar el estrangulamiento exterior, e incluso su contribución a agravarlo, y en su papel real y potencial en los procesos de integración regional" (Marinho, 1981, p. 9).${ }^{15}$ La IED y la presencia de las empresas transnacionales y su importancia, se reconocían entonces como algo inevitable, pero sólo podían tener un impacto positivo —en el sentido original de transitorio, regulado, y ocupando

\footnotetext{
${ }^{15}$ Marinho era funcionario de la Unidad Conjunta CEPAL/UnCTAD de Empresas Transnacionales.
} 
una posición restringida, aunque fundamental - si la estructura social y el estilo de desarrollo cambiaban. El abogar por las exportaciones de manufacturas y la continua promoción de la integración regional mantuvieron la idea original de la CEPAL de que para alcanzar el desarrollo, las industrias latinoamericanas, en una estructura social reformada, debían ser las fuerzas rectoras. No obstante, Aníbal Pinto reconoció que la participación de las empresas transnacionales era problemática, pero que con una regulación y presión adecuadas, dichas empresas podrían dirigirse hacia las actividades exportadoras, y por lo tanto no parecía correcto "rechazar de plano o escatimar en demasía la hipótesis de una mayor contribución de los consorcios foráneos en la diversificación industrial-exportadora". Ello, a la postre, dependería en gran medida de cómo se abordaran las políticas nacionales (Pinto, 1980, p. 140).

Estas propuestas se inscribieron en lo que pasó a conocerse como el "nuevo orden económico internacional". Éste, fuertemente asociado a la UNCTAD, y que podría pensarse como un resultado lógico de las ideas de Prebisch, pasó a ser el nuevo marco en que se esperaba que actuara la región. En la tercera evaluación regional, efectuada en Guatemala en 1977, surgió la idea de una nueva estrategia internacional de desarrollo en el marco del nuevo orden económico internacional. Se recomendaba "dar un fuerte impulso a los trabajos tendientes a elaborar un código internacional de conducta para las empresas transnacionales que norme sus actividades" (CEPAL, 1977, p. 43). Además, los gobiernos estaban ahora en mejor posición para negociar con esas empresas y controlarlas, ya que su experiencia les otorgaba más poder negociador. No sólo eso, sino que los países latinoamericanos debían intercambiar información a fin de incrementar su poder de negociación colectivo frente a ellas (ibid., p. 44). También debían elaborar medidas para promover la reestructuración de la producción industrial mundial, sobre todo asegurando un mayor acceso para las manufacturas provenientes de los países en desarrollo mediante la reducción de las restricciones comerciales y la regulación de la operación de las empresas transnacionales. Asimismo, debía otorgarse a los países en desarrollo acceso más fácil a la tecnología (ibid., p. 44). Pero, como siempre, eran las industrias y tecnologías latinoamericanas las que debían desarrollarse. Era imperativo establecer o fortalecer las instituciones de la región que hicieran investigación y desarrollo o que facilitaran su transferencia.

$\mathrm{Al}$ avanzar la década, las ideas de la CEPAL enfrentaban los desafíos más fuertes de su historia. En un clima políticamente polarizado, su postura reformista per- día atractivo. ${ }^{16}$ El Gobierno de los Estados Unidos había cambiado de actitud y apoyaba y alentaba las intervenciones militares para contener la amenaza comunista. Los movimientos guerrilleros en toda la región, un gobierno socialista en Chile y el movimiento organizado del nuevo orden económico internacional sólo habían polarizado más el entorno político internacional.

Esta situación llevó a una mayor radicalización y a más apoyo para la teoría de la dependencia. En el mundo desarrollado, las ideas económicas monetaristas ortodoxas ganaban terreno en la esfera académica y, hacia fines de la década, también en la política. En el decenio de 1950 había comenzado en los círculos académicos estadounidenses una campaña contra los "malos economistas", vale decir, aquellos vinculados con la CEPAL. Al tildar de no profesional a la escuela estructuralista, se lanzó un proyecto profesional para promover la economía "correcta" (es decir, monetarista) en América Latina. ${ }^{17}$ Así pues, la CEPAL se vio atrapada entre los críticos más radicales (seguidores de la teoría de la dependencia) y los monetaristas conservadores. Por otra parte, en el cono sur las brutales dictaduras militares aplicaban programas monetaristas y hacían los primeros esfuerzos por abandonar la estrategia impulsada por la industrialización. El caso de Chile es significativo: no sólo las ideas de la CEPAL habían cumplido un papel importante en la elaboración de políticas reformistas en Chile en la década de 1960, sino que su sede estaba ubicada en ese país. Estos ataques al estructuralismo de la CEPAL —así como los golpes militares del cono sur- podrían relacionarse con el choque entre la posición regulatoria y autónoma de la CEPAL y los intereses comerciales y de seguridad de los Estados Unidos. El fracaso de la Alianza para el Progreso había dado lugar a un cambio en la política exterior estadounidense que favorecía cada vez más las intervenciones militares y recelaba lo que el gobierno del país del Norte consideraba subversivo. Por último, dadas la situación crítica de la economía de los Estados Unidos y la competencia que representaban ahora Japón y Europa, cualquier intento por perjudicar los intereses comerciales estadounidenses - sobre todo en la región en que eran hegemónicosmerecía urgente atención.

\footnotetext{
${ }^{16}$ El reformismo de la CEPAL tenía sus límites, dado que era un organismo internacional y, teóricamente, siempre suponía que el Estado era un factor exógeno (Love, 1996b, p. 242).

${ }^{17}$ Lo que se hizo mediante la financiación y creación de nuevas instituciones y captando latinoamericanos para que asistieran a universidades de los Estados Unidos. El ejemplo más saliente de este proyecto es el acuerdo entre la Universidad de Chicago y la Universidad Católica de Chile. Véase Montecinos (1997).
} 
El decenio de 1970 también marcó un auge de la inversión extranjera, aunque ésta vino principalmente en forma de flujos financieros y deuda externa. La estrategia de "crecimiento impulsado por la deuda" ten- dría un abrupto fin en 1982. La región encaraba la necesidad de ajustar sus economías, haciendo frente al mismo tiempo a sus problemas de deuda en un entorno externo extremadamente desfavorable.

\section{$\mathrm{V}$ \\ Del ajuste de la deuda a la "transformación productiva": Ios atribulados decenios de 1980 y 1990}

Como la CEPAL estaba acorralada, el énfasis en el desarrollo y la producción cedió terreno a la oposición al tipo de ajuste exigido por los bancos de crédito y el FMI (Bielschowsky, 1998b, p. 37). La cuarta etapa en el pensamiento de la CEPAL tenía por objeto encontrar una salida para la región, que afrontaba el inevitable ajuste. Su principal propuesta fue buscar un "ajuste expansivo", para lo cual se hacía preciso un acuerdo entre los acreedores y los países latinoamericanos, así como un uso menos estricto de las políticas fiscal y monetaria. De acuerdo con la CEPAL, era la única manera en que se podía hacer el ajuste sin perjudicar más la situación social de la región.

A mediados del decenio de 1980 aparecieron nuevas reflexiones teóricas que trascendían los problemas del ajuste. Es la etapa que aún prevalece en el pensamiento de la CEPAL. Especialmente con los trabajos de Fernando Fajnzylber, la principal preocupación era evaluar nuevamente la experiencia de la estrategia de industrialización mediante la sustitución de las exportaciones y reflexionar sobre la factibilidad de una estrategia de industrialización (Fajnzylber, 1990). Fundamental en esta evaluación fue el éxito de los países de industrialización reciente de Asia oriental. Desde esta perspectiva, la CEPAL trató de enfrentar los problemas del pasado y encontrar una manera de remediarlos. La estrategia de industrialización mediante la sustitución de importaciones no había logrado resolver los problemas de la desigualdad social, sobre todo por su falta de absorción tecnológica. El ejemplo asiático permitió que la CEPAL mantuviera su interés tanto en la industrialización como en la intervención estatal. ${ }^{18}$

\footnotetext{
${ }^{18}$ Es interesante señalar que el Banco Mundial y el FMI han inter-
} pretado la experiencia asiática desde otra perspectiva y la han usa-
Estas ideas se cristalizarían en la propuesta de "transformación productiva con equidad" que marcaría los análisis de la CEPAL en el decenio de 1990 (CEPAL, 1990, p. 11). Lo que hacía falta ahora era una "nueva industrialización" que hiciera hincapié en la necesidad del "progreso tecnológico". En la década de 1990, la necesidad de una estrategia externa competitiva complementó estas ideas tempranas. "La industrialización constituye el eje de la transformación productiva" (ibid., p. 14). Según esta nueva estrategia, América Latina debía encarar los problemas de la pobreza y la desigualdad con firmes medidas redistributivas (ibid., p. 15).

En el decenio de 1990 la posición de la CEPAL no tuvo fuerza frente al predominio de las ideas plasmadas en el Consenso de Washington. Tales ideas habían cobrado importancia gracias a los oficios del Fondo Monetario Internacional (FMI) y el Banco Mundial durante la década de 1980, dado que estas instituciones desempeñaron un papel preponderante en el proceso de negociación de la deuda de esa década y en los procesos de reforma estructural de la década siguiente. Además, los intentos por desprestigiar las ideas estructuralistas, iniciados como vimos en el decenio de 1950, finalmente habían prosperado, ya que los economistas capacitados en esos programas ocupaban ahora los más altos puestos en los gobiernos latinoamericanos. El fin de la guerra fría (1989-1991), con el predominio de los Estados Unidos, no hizo más que fortalecer y respaldar esas ideas. Por otra parte, debido a este predominio, las propuestas de la CEPAL

do para justificar sus propuestas de libre mercado. Véase Banco Mundial (1993). 
habían perdido el ya débil apoyo de que gozaban. ${ }^{19}$ En este clima, la CEPAL debió responder y adaptar sus ideas.

Un elemento importante de este nuevo período y del intento de hacer frente a un clima político e intelectual hostil y exigente fue que, aun reconociendo los problemas, deficiencias y abusos de la industrialización sustitutiva - en especial los aspectos negativos de la intervención estatal y la falta de interés en las fuerzas del mercado-, la CEPAL evaluó de manera positiva sus logros reales. Esto fue esencial, dado que el pensamiento neoliberal culpaba a la estrategia sustitutiva por el aparente fracaso económico de la región, ${ }^{20}$ y sostenía que su resultado había sido la aparición de industrias ineficientes que habían impedido el desarrollo económico latinoamericano. En este sentido, la propuesta del Consenso de Washington fue dejar actuar libremente a las fuerzas del mercado y abrir las economías para recuperar la eficiencia. Todo fomento de la industria se consideraba "populista" y por ende negativo (Dornbusch y Edwards, 1991).

Para la CEPAL, América Latina no sólo había registrado altas tasas de crecimiento durante la "edad dorada" (1950-1973), sino que la industrialización mediante la sustitución de importaciones había sido más positiva de lo que se pensaba antes, en términos de aprendizaje y desarrollo tecnológico. Esto constituía una sólida base desde la cual la región podía emprender una transformación hacia un sector industrial más dinámico, competitivo y orientado hacia el exterior (Katz, 1998, pp. 63-75).

El decenio de 1990 también marca el retorno de los países latinoamericanos a los mercados financieros internacionales, tras la crisis de la deuda. En el decenio anterior se había producido una caída de los flujos que ingresaban a la región y del porcentaje del total de los flujos internacionales que ésta recibía. ${ }^{21}$ Además, en la década de 1990 la situación económica internacional se caracteriza por el aumento de los flujos de IED, en los cuales las ahora llamadas "economías emergentes" cumplen un papel importante. ${ }^{22}$ Los pro-

\footnotetext{
${ }^{19}$ Un ejemplo evidente de ello es la actual propuesta del área de libre comercio de las Américas, encabezada por el Gobierno de los Estados Unidos.

${ }^{20}$ Por ejemplo, Arnold Harberger piensa que la situación de América Latina mejoró cuando la "buena economía" (aquella impartida en la Universidad de Chicago) reemplazó a la "mala economía" de la CEPAL. Véase Harberger (1996, p. 303).

${ }^{21}$ A partir de 1991, por primera vez desde el comienzo de la crisis de la deuda, se registró una transferencia neta positiva de recursos hacia la región (CEPAL, 1995, p. 26).

${ }^{22}$ En 1998 los flujos habían llegado a los 650000 millones de dólares. Aun así, el grueso de los flujos de capital se dirigía a las economías desarrolladas. En 1997 esa proporción correspondía al $59 \%$, y en 1998 al $71 \%$ del total. Véase CEPAL (2000).
}

cesos de privatización en América Latina resultan ser un excelente polo de atracción de dichos flujos. La IED y las empresas transnacionales se consideran elementos deseables de una buena situación económica, a la luz del consenso neoliberal predominante. En una economía abierta y globalizada, los gobiernos deben facilitar y crear buenas condiciones para atraerlas. Las políticas que lo impiden o procuran alentar las industrias nacionales se consideran contraproducentes e inseguras, de acuerdo con el Consenso de Washington.

La inversión extranjera en la década de 1990 tendió a dirigirse más bien a los servicios y las inversiones productivas, a diferencia de los préstamos de bancos comerciales que constituían la mayor parte de la inversión a fines del decenio de 1970 (CEPAL, 2000, p. 27). Estos cambios propiciaron un renovado interés por las empresas transnacionales en los estudios de la CEPAL. Un hallazgo importante fueron los cambios observados en la participación de esas empresas en las economías latinoamericanas a lo largo de las últimas décadas (Stumpo, 1998). Si bien durante los años de la industrialización sustitutiva de las importaciones las empresas transnacionales tendieron a invertir en bienes intermedios y de consumo, desde mediados de 1970 y principios de 1980, mientras los gobiernos latinoamericanos buscaban transformar la estrategia sustitutiva, el grueso de la IED se dirigió a las manufacturas primarias de exportación. Tal conclusión respalda el argumento original de la CEPAL de que las empresas transnacionales no pueden ser las fuerzas rectoras del desarrollo. Por más importantes que ellas sean, la necesidad de industrias tecnológicamente avanzadas sólo puede satisfacerse desde la propia América Latina.

Contrariamente a lo que sostiene el Consenso de Washington, al reconocer los beneficios de la industrialización mediante la sustitución de importaciones, tomar el ejemplo de Asia oriental y mostrar las deficiencias de los beneficios de las empresas transnacionales, la CEPAL sigue promoviendo políticas positivas que puedan ayudar a las industrias latinoamericanas, admitiendo siempre la necesidad de abrir las economías y liberar más el mercado. El imperativo es fomentar que las industrias latinoamericanas absorban la última tecnología, para que puedan competir en el ámbito internacional. Aunque las empresas transnacionales puedan contribuir a fomentar las exportaciones en determinados períodos y sectores, la solidez de la posición de la región en los mercados internacionales "depende de la existencia y del avance de empresas nacionales capaces de competir - solas o con aportes de capital extranjero- con las empresas que abastecen los 
mercados internacionales" (CEPAL, 1990, p. 77). La transformación productiva con equidad debe ocurrir en un contexto de alta competitividad internacional, sustentada en una "incorporación deliberada y sistemática del progreso técnico". Ello implica que "debe reconocerse la dimensión de aprendizaje y difusión de los conocimientos disponibles a nivel internacional" (ibid., p. 14). Es preciso absorber tanto los adelantos tecnológicos como los de capital humano, a fin de mejorar la productividad, la competitividad y la equidad. De acuerdo con la CEPAL, éste es un aspecto que ha sido descuidado en América Latina.

Los estudios en que se analizan las empresas transnacionales y los flujos de IED en la región durante el decenio de 1990 ayudan a la CEPAL a resistirse al rechazo a apoyar a las industrias latinoamericanas sugerido por el Consenso de Washington. Como en las primeras etapas, se espera que las empresas transnacionales y la IED tengan efectos positivos, y hay clara conciencia de la necesidad de alentar y atraer el capital y la tecnología extranjeros, pero, según la CEPAL, éstos nunca serán sustitutos de las industrias latinoamericanas, si la región desea desarrollarse y enfrentar sus problemas sociales. Otro elemento importante en la visión

\section{VI}

\section{Conclusiones}

Como muestra el ejemplo del decenio de 1990, la CEPAL sigue en pos de promover una estrategia de desarrollo basada en la industria y la tecnología modernas y con la cual América Latina pueda seguir un camino autónomo hacia el desarrollo y la equidad. En el medio siglo que hemos considerado, la economía de América Latina y del mundo ha cambiado apreciablemente. En cada período examinado, las relaciones de América Latina con la economía internacional y con la inversión extranjera adoptaron distintas formas. En la última década considerada, la de 1990, también las

\footnotetext{
${ }^{23}$ Hasta la crisis de la deuda del decenio de 1980, las exportaciones intrarregionales se habían duplicado como porcentaje del total de las exportaciones de las industrias latinoamericanas. Sin embargo, su principal desventaja era no poder proporcionar a la industrialización mediante la sustitución de importaciones, particularmente en los países pequeños y medianos, la "masa crítica" de mercado y el grado de competitividad necesarios para tener éxito en el largo plazo (Ffrench-Davis, Muñoz y Palma, 1998, p. 213).
}

cepalina es su interés en el ejemplo dado por las empresas transnacionales latinoamericanas, que han logrado crecer y expandirse, y que de hecho se consideran posibles fuentes de dinamismo económico (Chudnovsky, 1999). Así es posible mantener otra vieja idea: la importancia y conveniencia de la integración regional. Pese a sus débiles avances, la integración regional ha ayudado a promover el comercio de manufacturas en toda la región. ${ }^{23}$

Por último, los ingentes flujos de IED que ingresaron a la región a partir del decenio de 1990 han renovado la importancia de contar con cierto tipo de regulación. Obviamente, se reconoce que la regulación estatal es necesaria, pero está debilitada por la falta de información adecuada. Recuperando la vieja idea de la importancia de la información y la experiencia que los gobiernos necesitan para tener poder de negociación frente a las empresas transnacionales, la CEPAL promueve estudios que puedan ayudar a los gobiernos latinoamericanos a regular dichas empresas y la IED. Por ejemplo, en 1999 se reconocieron dos deficiencias: la falta de evidencias estadísticas y los desafíos normativos, dados los múltiples canales y acuerdos por los que fluye la IED (CEPAL, 2000, p. 29). tendencias ideológicas estuvieron muy lejos de coincidir con las ideas cepalinas. La globalización, la IED y la participación de las empresas transnacionales se consideran actualmente medios de desarrollo deseables para los "países emergentes". ${ }^{24}$ Sin embargo, la CEPAL continúa su esfuerzo por entender estos cambios dentro del mismo marco y sobre la base de los mismos supuestos que tenía originalmente. Al hacerlo, procura preservar su propio concepto de lo que debería ser una estrategia de desarrollo latinoamericana. Estos supuestos y su marco dan forma a la visión cepalina de la naturaleza de las inversiones extranjeras.

En el presente artículo se ha demostrado que la posición de la CEPAL frente a las empresas transna-

\footnotetext{
${ }^{24}$ Excepción hecha, por cierto, de los "globalifóbicos", curiosa denominación que dio el ex presidente de México Ernesto Zedillo a quienes hacen manifestaciones en cada reunión de líderes internacionales.
} 
cionales y la IED ha sido coherente y consistente durante sus cinco décadas de vida. Esta posición implicó el reconocimiento de la necesidad de contar con inversión extranjera, pero a la vez el reconocimiento de los peligros y desventajas de depender indiscriminadamente del capital foráneo. También se ha demostrado que, pese a tener continuidad, el análisis de la CEPAL se ha adaptado y ha respondido a cambiantes condiciones económicas e ideológicas, pero sin comprometer su posición fundamental.

Los temas de la IED y las empresas transnacionales son complejos y fundamentales en América Latina y las perspectivas de interdependencia y aumento del comercio internacional tienden a otorgarles aún más importancia. En una era en que el consenso teórico propende a desestimar la preocupación por la naturaleza problemática de la IED y reemplazarla con la fe ciega en la apertura de los mercados, y cuando los problemas y la vulnerabilidad de la región parecen aumentar, el esfuerzo crítico de la CEPAL, si se le entiende en su propio marco, es una voz potente que intenta encararlos y ayudar a resolverlos.

(Traducido del inglés)

\section{Bibliografía}

Arndt, H.W. (1987): Economic Development. The History of an Idea. Chicago, Illinois, Chicago University Press.

Banco Mundial (1993): The East Asian Miracle: Economic Growth and Public Policy, Washington, D.C.

Bielschowsky, Ricardo (1998a): Cincuenta años del pensamiento de la CEPAL: una reseña, Cincuenta años de pensamiento en la CEPAL. Textos seleccionados, vol. 1, Santiago de Chile, CEPAL. (1998b): Evolución de las ideas de la CEPAL, Revista de la CEPAL, número extraordinario, LC/G.2037-P, Santiago de Chile, octubre.

Bulmer-Thomas, Victor (1994): The Economic History of Latin America since Independence. Nueva York, Cambridge University Press.

Cardoso, Fernando H. (1973): Associated-dependent development: Theoretical and practical implications, en Alfred Stepan (comp.), Authoritarian Brazil: Origins, Policies, and Future, New Haven, Yale University Press.

CEPAL (Comisión Económica para América Latina y el Caribe) (1954): La cooperación internacional en la política de desarrollo latinoamericana, E.CN.12/359, Nueva York. Publicación de las Naciones Unidas, $\mathrm{N}^{\circ}$ de venta: 54.II.G.2.

(1969): América Latina. El pensamiento de la CEPAL, Santiago de Chile, Editorial Universitaria.

(1977): Estrategia internacional de desarrollo y establecimiento de un Nuevo Orden Económico Internacional. Tercera evaluación regional, 1977, Cuadernos de la CEPAL, $\mathrm{N}^{\circ} 17$, Santiago de Chile.

(1979): América Latina en el umbral de los años 80, E/ CEPAL/G.1106, Santiago de Chile.

(1981): Nota de la Dirección, Revista de la CEPAL, № 14, E/CEPAL/G.1179, Santiago de Chile, agosto.

(1990): Transformación productiva con equidad: la tarea prioritaria del desarrollo de América Latina y el Caribe en los años noventa, LC/G.1601-P, Santiago de Chile. Publicación de las Naciones Unidas, $\mathrm{N}^{\circ}$ de venta: S.90.II.G.6.

(1995): La inversión extranjera en América Latina y el Caribe. Informe 1995, LC/G.1890, Santiago de Chile. (1998): La inversión extranjera en América Latina y el Caribe. Informe 1997, LC/G.1985-P, Santiago de Chile. Publicación de las Naciones Unidas, $\mathrm{N}^{\circ}$ de venta: S.97.II.G.7. (2000): La inversión extranjera en América Latina y el Caribe. Informe 1999, LC/G.2061-P, Santiago de Chile. Publicación de las Naciones Unidas, $\mathrm{N}^{\circ}$ de venta: S.00.II.G.4.

Chudnovsky, Daniel (comp.) (1999): Las multinacionales latinoamericanas. Sus estrategias en un mundo globalizado, Buenos Aires, Fondo de Cultura Económica.
Dornbusch, Rudiger y Sebastián Edwards (1991): The macroeconomics of populism in Latin America, Chicago, Chicago University Press.

Dosman, Edgar J. y David H. Pollock (1998): Hasta la UNCTAD y de regreso: divulgando el evangelio, 1964-1968, Estudios sociológicos del Colegio de México, vol. 16, № 48, septiembre-diciembre.

Fajnzylber, Fernando (1990): Industrialización en América Latina: de la "caja negra" al "casillero vacío", serie Cuadernos de la CEPAL, N 60, LC/G.1534/Rev.1-P, Santiago de Chile, CEPAL. Publicación de las Naciones Unidas, $\mathrm{N}^{\circ}$ de venta: S.89.II.G.5

Ffrench-Davis, Ricardo, Oscar Muñoz y Juan G. Palma (1998): The Latin American economies, 1950-1990, en Leslie Bethell (comp.), Latin America. Economy and Society since 1930, Cambridge, Cambridge University Press.

Harberger, Arnold (1996): Latin America en A.W. Coats, The Post1945 Internationalization of Economics. Annual Supplement to Volume 28. History of Political Economy, Durham, Duke University Press.

Hirschman, Alfred (1961): Ideologies of economic development in Latin America, en A. Hirschman (comp.), Latin American Issues. Essays and Comments. Nueva York, Twentieth Century Fund.

Katz, Jorge (1998): Aprendizaje tecnológico ayer y hoy, Revista de la CEPAL, número extraordinario, LC/G.2037-P, Santiago de Chile, octubre.

Love, Joseph L. (1996a): Crafting the Third World. Theorizing underdevelopment in Rumania and Brazil, Stanford, Stanford University Press.

(1996b): Economic ideas and ideologies in Latin America since 1930, en Leslie Bethell, Ideas and Ideologies in Latin America, Cambridge, Cambridge University Press.

(1996c): Las fuentes del estructuralismo latinoamericano, Desarrollo económico, vol. $36, \mathrm{~N}^{\circ} 141$, abril-junio.

Marinho, Luis C. (1981): Las empresas transnacionales y la actual modalidad de crecimiento económico, Revista de la CEPAL, $\mathrm{N}^{\circ}$ 14, E/CEPAL/G.1179, Santiago de Chile, agosto.

Montecinos, Verónica (1997): Los economistas y las elites políticas en América Latina, Estudios internacionales, año 30, $\mathrm{N}^{\circ} 119-120$, julio-diciembre.

Painter, David (1999): The Cold War. An international history, Londres, Routledge.

Pinto, Aníbal (1976): Notas sobre los estilos de desarrollo en América Latina, Revista de la CEPAL, $\mathrm{N}^{\circ} 1$, Santiago de Chile, primer semestre. 
(1980): La internacionalización de la economía mundial. Una visión latinoamericana, Madrid, Ediciones de Cultura Hispánica.

Prebisch, Raúl (1949): El desarrollo económico de América Latina y algunos de sus principales problemas, E/CN.12/89, Santiago de Chile.

(1963): Hacia una dinámica del desarrollo latinoamericano: con un apéndice sobre "el falso dilema entre desarrollo económico y estabilidad monetaria”, México, D.F., Fondo de Cultura Económica.

(1981) Capitalismo periférico. Crisis y transformación, México, D.F., Fondo de Cultura Económica.
Stumpo, Giovanni (comp.) (1998): Empresas transnacionales. Procesos de reestructuración industrial y políticas económicas en América Latina, Buenos Aires, CEPAL/Alianza Editorial.

Sunkel, Osvaldo (1998): Desarrollo, subdesarrollo, dependencia. Marginación y desigualdades espaciales: hacia un enfoque totalizante, en Ricardo Bielchowsky, Cincuenta años del pensamiento de la CEPAL. Textos seleccionados, vol. 1, Santiago de Chile, CEPAL.

Williamson, John (comp.) (1990): Latin American Adjustment. How much has happened?, Washington, D.C., Instituto de Economía Internacional. 
